Stoa

Vol. 9, no. 18, 2018, pp. 103-126

ISSN 2007-1868

\title{
HEIDEGGER: "MI ATAQUE (ANGRIFF) CONTRA HUSSERL" METAFÍSICA Y ANTISEMITISMO
}

\author{
Julio Quesada \\ Instituto de Filosofía \\ Universidad Veracruzana \\ quesadajulio@yahoo.es
}

RESUMEN: Este estudio gira en torno de un texto de Heidegger perteneciente a los Cuadernos negros en donde el filósofo explica en qué consiste el "desarraigo" de la "cultura" y "espíritu" alemanes (y occidentales). Poniendo en relación su antisemitismo con la crítica a la metafísica como olvido del Ser.

PALABRAS CLAVE: Ser $\cdot$ metafísica $\cdot$ raza $\cdot$ Husserl $\cdot$ ataque $\cdot \operatorname{verdad} \cdot \operatorname{maquina}$ ción

ABSTRACT: This essay deals with a particular section of Heidegger's Black Notebooks in wichthe autor have explained the meaning of the "uprooting" of the German (and Western) "culture" and "spirit". This way, a relationship between his anti-semitism and his critique of metaphysics as a forgot of the Being is established.

KEYWORDS: Being $\cdot$ Metaphysics $\cdot$ Race $\cdot$ Husserl $\cdot$ Attack $\cdot$ Truth $\cdot$ Maquination

Hacia los colegas y amigos: Antonio Zirión e Ignacio Quepons

Soy el pequeño judío que escribió la Biblia. He visto las naciones levantarse y caer. He oído sus historias. las he oído todas. Pero el amor es el único motor de supervivencia.

Leonard Cohen 


\section{El texto en alemán Überlegungen XII-XV (Schwarze Hefte} 1939-1941), GA 96, Klostermann, Frankfurt, 2014, p. 44-47 es el siguiente

Die Geschichte des abendländischen Menschen -gleichgültig ob er sich in Europa aufhält oder anderswo- hat sich langsam auf eine Lage vorgeschoben, in der alle sonst vertrauten Bezirke wie "Heimat", "Kultur", "Volk", aber auch "Staat" und "Kirche", aber auch "Gesellschaft" und "Gemeinschaft." die Zuflucht verweigern, weil sie selbst zu bloßen Vorwänden herabgesetzt und dem beliebigen Vorschub preisgegeben sind, dessen bewegende Mäcli- Le unkenntlich bleiben und ihr Spiel lediglich darin verraten, daß sie den Menschen in die Gewöhnung zur je aufdringlicheren Massenhaftigkeit zwingen, deren "Glück" sich darin erschöpft, ohne Entscheidungen auszukommen und in der Meinung sich zu betäuben, immer mehr in ihren Besitz und Genuß zu bringen, weil das Besitzwürdige stets geringer und gehaltloser wird. Die einzige und dazu notwendig unechte Angst, die eine solche Lage noch zuläßt, ist die Furcht, dieser Menschenbetrieb könnte durch neue Kriege plötzlich ein linde nehmen und alles abhanden kommen; denn wo die Versteifung auf das Vorhandene als Besitz und Beherrschung des Seienden gilt, schrumpft das Unglück auf den Zustand ein, in dem und durch den alles Vorhandene der Beseitigung unterliegen muß.

Wo könnte hier noch eine Spur jener Angst erwachen, die erkennt, daß eben die Vormacht des Vorhandenen und die Unbe- dürftigkeit gegenüber Entscheidungen, das ungreifbar um sich greifende Anwachsen der Bestimmung zu dieser Lage bereits und allein nicht nur Zerstörung, sondern die Verwüstung ist, deren Herrschaft durch Kriegskatastrophen und Katastrophenkriege nicht mehr angetastet, sondern nur noch bezeugt werden kann. Ob das Herdenwesen des Menschen, sich selbst überlassen, durch seine Vergemeinerung den Menschen zur Vollendung seiner Tier- heit treibt, oder ob Rudel von Gewalthabern die auf das Höchste durchgegliederten und »einsatzbereiten« Massen der völligen Entscheidungslosigkeit zujagen, ob also eine "Rangordnung" innerhalb des endgültig festgestellten Tieres im Sinne des

"Übermenschen" noch aufgezüchtet werden kann oder nicht, das bringt in den metaphysischen Charakter des Seienden im Ganzen keine wesentliche Änderung. Mit der kältesten Kühnheit und unter Abwehr je- 
des Zudrängens "moralischer" Wertungen und "pessimistischer" Stimmung muß der denkerische Blick die Vollendung der metaphysischen Geschichte des Seienden vor und um sich haben, damit die Luft für anfängliche scheidungen rein und klar das Fragen der Besinnung durchwehe.

$\mathrm{Zu}$ wissen gilt hier, daß die Verwüstung innerhalb der Bezirke der "Bildung" und des "Kulturbetriebes" schon wesentlich weiter fortgeschritten ist als im Feld der gröberen Besorgung der Lebensbedürfnisse. Entsprechend hat sich hier -bei den vergeblichen Hütern des geistigen Erbes- eine höhere Geschicklichkeit im Verzicht auf wesentliche Besinnung ausgebildet. In die Entsprechung locken und steigern sich auf der einen Seite die Entmach- tung aller Verwurzelungsbereiche zugunsten der Ermächtigung der durchgängigen Machenschaft und auf der Gegenseite der Verzicht des Massenmenschentums auf alle Entscheidungs- und Maßstabsansprüche. Durch diese sich auswcitende Entsprechung entsteht eine unsichtbare Leere, deren verborgenes Wesen aus der noch leitenden metaphysischen Grundstellung nicht begriffen werden kann, zumal sie sich im Anschein ihres Gegenteils zum Ansehen bringt: als bedingungslose Eingliederung des Menschen in die Machenschaft des Seienden im Ganzen - dies oft noch unter Berufung auf - geschichtliche Herrschaftsformen, denen bereits jeder Boden weggezogen ist- z.B. meint heutiges Soldatenturn noch auf "Preußentum" sich berufen zu können; es ist im Wesen gewandelt und sogar schon etwas anderes als der Krieger der letzten Weltkriegsjahre -abgesehen davon, daß aus diesem Bereich menschlichen Handelns, wenngleich er in einer eigengefügten Härte vor den Tod stellt, schöpferische geschichtliche Entscheidungen nie entspringen können- sondern nur Formen einer stets mittel-haften Zucht, die ins "Totale" erweitern zu wollen, einer groben Unwissenheit um das Wesen des Seyns und seiner Jenseitigkeit zur Macht und Ohnmacht gleichkommt.

Aus demselben Grunde aber ist auch jeder "Pazifismus" und jeder "Liberalismus" außerstande, in den Bezirk wesentlicher Entscheidungen vorzudringen, weil er es nur zum Gegenspiel gegen das echte und unechte Kriegertum bringt. Die zeitweilige Macht- sLeigerimg des Judentums aber hat darin ihren Grund, daß die Metaphysik des Abendlandes, zumal in ihrer neuzeitlichen Entfaltung, die Ansatzste- 
lle bot für das Sichbreitmachen einer sonst leeren Rationalität und Bechenfähigkeit, die sich auf solchem Wege eine Unterkunft im "Geist" verschaffte, ohne die verborgenen Iwitscheidungsbezirke von sich aus je fassen - zu können. Je ursprünglicher und anfänglicher die künftigen Entscheidungen und Fragen werden, umso unzugänglicher bleiben sie dieser "Rasse". (So ist Husserls Schritt zur phänomenologischen Betrachtung unter Absetzung gegen die psychologische Erklärung und historische Verrechnung von Meinungen von bleibender Wichtigkeit - und dennoch reicht sie nirgends in die Bezirke wesentlicher Entscheidungen, setzt vielmehr die historische Überlieferung der Philosophie überall voraus; die notwendige Folge zeigt sich alsbald im Einschwenken in die neukantische Transzendentalphilosophie, das schließlich einen Fortgang zum Hegelianismus im formalen Sinne unvermeidlich machte. Mein "Angriff” gegen Husserl ist nicht gegen ihn allein gerichtet und überhaupt unwesentlich- der Angriff geht gegen das Versäumnis der Seinsfrage, d. h. gegen das Wesen der Metaphysik als solcher, auf deren Grund die Machenschaft des Seienden die Geschichte zu bestimmen vermag. Der Angriff gründet einen geschichtlichen Augenblick der höchsten Entscheidung zwischen dem Vorrang des Seienden und der Gründung der Wahrheit des Seyns.)

\section{Nuestra propuesta de traducción}

La historia del hombre occidental -sin importar si reside en Europa o en algún otro lado- se ha desplazado hacia una situación en la que dominios conocidos como "patria”, "cultura", "pueblo", pero también "Estado" e "Iglesia", así como "sociedad" y "comunidad" deniegan el refugio, ya que ellas mismas son reducidas a meros pretextos y se encuentran sujetas a cualquier avance, cuyos poderes en movimiento permanecen irreconocibles y sólo delatan su juego, en que obligan a los hombres hacia una habituación a las grandes cantidades cada vez más intrusivas, cuya "felicidad" se reduce a un poder vivir sin decisiones y aturdirse con la opinión de traer cada vez más hacia su propiedad

y disfrute, porque lo digno de poseer se vuelve cada vez más escaso y más insustancial. El único miedo, y para ello necesariamente irreal, que todavía permite tal situación, es el temor que este funcionamiento del hombre podría llegar a su fin por nuevas guerras y todo podría perderse; ya que donde la rigidez de lo existente se considera como 
propiedad y dominio del ente, se contrae la desdicha a una situación en la cual y a través de la cual todo lo existente se vuelve sujeto a la eliminación.

Dónde podría aquí despertar todavía una pizca de aquel temor, que reconoce que precisamente la hegemonía de lo existente y la falta de indigencia frente a las decisiones, la ampliación intocable de la disposición tan sólo hacia esta situación no sólo constituye la destrucción, sino la devastación, cuyo dominio no puede afectarse por catástrofes de guerra y guerras catastróficas, sino sólo puede ser testimonio de la misma. Si la naturaleza gregaria del hombre, abandonado a su propia merced, a través de su comunicación empuja al hombre a la perfección de su esencial animal, o si las manadas de gobernantes quienes en lo más alto cazan las masas estructuradas y "disponibles" de una completa falta de decisión, si podrá generarse o no por lo tanto, una "jerarquía" dentro del animal definitivamente determinado en el sentido de "los hombres superiores", eso no constituye una diferencia esencial en el carácter metafísico del ser en su totalidad. Con la osadía más fría y rechazando cualquier afluencia de valoración "moral" y estado de ánimo "pesimista", la mirada filosófica tiene que tener enfrente y a su alrededor la perfección de la historia metafísica del ser, para que el aire para tomar las decisiones iniciales sople de manera clara y pura por las preguntas de la reflexión.

Lo que hay que saber aquí es que la devastación dentro de las áreas de la "educación" y del "sector cultural" se ha consolidado mucho más que en el campo de la satisfacción más rudimentaria de las necesidades básicas. De manera correspondiente, se ha desarrollado aquí -con los inútiles guardianes de la herencia espiritual- una habilidad mayor de renunciar a la reflexión esencial. En esta correlación se atraen y se intensifican por un lado el derrocamiento de todas las áreas de arraigo a favor del empoderamiento de acciones universales, y por otro lado, de la renuncia del hombre masa a todas las pretensiones de decisión y de norma. A través de esta analogía, cada vez más amplia, surge un vacío invisible cuya esencia ocultada no puede entenderse desde la posición metafísica inicial que todavía rige, sobre todo porque recibe su reputación por las apariencias de su opuesto: como la incorporación del hombre a las acciones del ser en su totalidad -frecuentemente apelando incluso a las formas de dominio, de las que ya se ha removido 
cualquier fondo- por ejemplo, la actual soldadesca cree poder acogerse aún al "Prusianismo"; su naturaleza ha cambiado y es ahora incluso algo diferente que el guerrero de los últimos años de guerra mundial -además del hecho de que desde este ámbito de la acción del hombre, si bien antepone a la muerte en una penuria causada por sí mismo, no podrán jamás surgir decisiones históricas creativas- sino sólo formas de un cultivo siempre fundamentales, de querer ampliarlas hacia lo "total", de una ignorancia burda de la esencia del ser y que equivale a lo ulterior del poder y de la impotencia.

Por la misma razón, sin embargo, tampoco el "pacifismo" y cualquier forma de "liberalismo" son capaces de avanzar hacia el dominio de las decisiones esenciales, porque sólo lo presenta como contraste entre la milicia auténtica y no auténtica. El temporal aumento en el poderío del judaísmo se debe, no obstante, a que la metafísica del occidente, sobre todo en su desenvolvimiento moderno, ofrecía un punto de partida para que se propagara una racionalidad y habilidad aritméticas por lo demás vacías, que por tales medios logra alojarse en el "espíritu", sin poder entender jamás los dominios de decisión. Mientras las decisiones y preguntas futuras se vuelven más fundamentales y esenciales, más inaccesibles permanecen para esta "raza". (De esta manera, el paso hacia la reflexión fenomenológica de Husserl mantiene su importancia bajo la crítica contra la explicación psicológica y compensación histórica de opiniones -y aun así no llega para nada a los dominios de las decisiones esenciales, sino [que] presupone más bien la tradición histórica de la filosofía donde quiera; el resultado necesario se muestra pronto en el alineamiento con la filosofía trascendental neokantiana, que al fin y al cabo hace inevitable una partida hacia el hegelianismo en el sentido formal. Mi "ataque" contra Husserl no se dirige sólo hacia él y es de cualquier manera insignificante- el ataque va en contra de la omisión de la pregunta por el ser, es decir, contra la esencia de la metafísica como tal, que busca determinar la historia basada en las maquinaciones sobre el ser. El ataque establece un momento histórico de la más elevada decisión entre (Vorrang) la prioridad del ser y el establecimiento de la verdad del ser (Seyn).

Agradezco la ayuda recibida de los profesores Antonio Zirión e Ignacio Quepons; lo que no significa que ellos sean responsables de mis errores. 


\section{Notas metafísicas, metapolíticas y apuntes biográficos para un comentario de texto}

El problema del Ser no es otro que el desarraigo de Europa, gerifalte del mundo. La ausencia de raíces (existencia ontológico-histórica: Ser y tiempo (1927). Ya tenemos ahí un definitivo principio, arché, sobre la jerarquización del Ser. La pregunta fundamental de la metafísica (Introducción a la Metafísica de 1935): “¿Por qué hay Ser y no más bien Nada?”, tiene su genealogía histórica (historicidad), su comienzo y razón de existir en Europa, Occidente; pero, desde 1933, y de forma implícita desde los años 20 (Informe Natorp), exclusivamente en el Volk alemán -todo un pleonasmo- porque éste es el único pueblo metafísico que queda en la Tierra.

El problema del Ser es el del desarraigo (Nihilismo) que se ha apoderado de "dominios" (Heidegger no utiliza el término "concepto") tan decisivos para el nuevo nacionalismo alemán como "patria", "pueblo", "cultura", "Estado" e "Iglesia". Dominios a los que podríamos añadir, a la luz de la obra heideggeriana, otros como "comunidad", "sujeto", "lengua" y "muerte". El Nihilismo consiste en la destrucción de las formas "propias" de la existencia humana que, según Sein und Zeit, es un encadenamiento tan limitado y mortal como irreferente. A esta cadena la podemos nombrar, siguiendo la analítica ontológica, con sus términos: Dasein-Boden-Blut-Volk-Schprach-Tod-Staat. En la Verdad de la diferencia del Ser no se des-vela un sujeto moderno, una persona o individuo o alma; sino el propio encadenamiento del Ser como forma "propia". Por lo tanto, el primado ontológico del $D a$ sein no obedece a las revoluciones burguesas modernas empeñadas en salvar la subjetividad y autonomía del individuo frente a la totalidad del estado; sino a la "revolución conservadora" que el Ser estaba llevando a cabo en Alemania mucho antes que el nacionalsocialismo y el antisemitismo se hicieran con el poder oficial de la nación. Este principio ontológico-histórico en el que se des-vela el Dasein (estar-yaaquí) en calidad de comunidad-del-pueblo-en-su-Estado. Una comunidad existencial-nacional que se opone tanto a la tentativa "comunista" de la República de Platón, comunismo de las Ideas y proporcionalidad geométrica, como al desarrollo moderno de la comunidad que

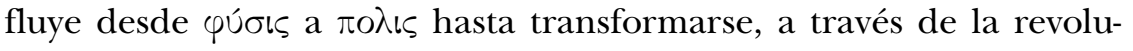


ciones modernas ilustradas (Inglaterra, Estados Unidos y Francia) en "sociedad civil" con plena autonomía ante el Estado. La radical crítica de Heidegger a la modernidad en todos sus sentidos (filosófico, científico-técnico, religioso y político) se mide en comparación a cómo el desarraigo que "es" la modernidad como cumbre del Nihilismo que ya apunta desde el comienzo de la filosofía en tanto "teoría" e "idea". Por ejemplo, toda teoría del conocimiento que, a juicio de Heidegger, y por su carácter universalista, ya estaría olvidando la pregunta por el Ser, por la existencia singular, única e irreferente (como la muerte) del Ser. Así, pues, aquel frontispicio que Platón -y a la luz del movimiento órfico-pitagórico (semita) - puso para la Academia, "Nadie entre aquí sin saber matemáticas", es considerado por Heidegger como el inicio de la historia del olvido del Ser. Luego, por lógica, podemos adelantar que Ser para Heidegger es una "decisión" por la cultura, la sociedad, la comunidad, la patria, la lengua, la muerte, el pueblo, el Estado y la Iglesia radicalmente a) finitos y b) excluyentes.

En este sentido el Discurso de Rectorado de 1933 -La autoafirmación de la Universidad alemana- es una auténtica mina para comprender que el problema del Ser remite al problema alemán de una cultura propiamente alemana, exclusivamente alemana, hasta el punto ontológico-histórico (historicidad) de haber identificado en ese texto al "espíritu" con el "cuidado" (Sorge) de la Kultur; en el entendido, obvio, de que la cultura es un patrimonio exclusivo del pueblo alemán. Salvando a la cultura alemana de sus enemigos se salva, al mismo tiempo, no solo la existencia de Alemania sino la del Ser.

Escribió y dijo Heidegger:

Pues "espíritu" no es ni la sagacidad vacía, ni el juego de ingenio que a nada compromete, ni el ejercicio sin fin del análisis intelectual, ni una razón universal, sino que espíritu es el decidirse, originariamente templado y consciente, por la esencia del ser. Y el mundo espiritual de un pueblo no es una superestructura cultural como tampoco un arsenal de conocimientos y valores utilizables, sino que es el poder que más profundamente conserva las fuerzas de su raza y de su tierra, y que, como tal, más íntimamente exalta y más ampliamente conmueve su existencia. Sólo un mundo espiritual garantiza al pueblo la grandeza; pues obliga a que la permanente decisión entre la voluntad de grandeza y el dejarse llevar a la decadencia sea la ley que rige la marcha que nuestro pueblo ha emprendido hacia su historia futura (Heidegger 1989, p. 12-13. Cursivas en el original). 
Retrospectivamente vemos con claridad que la "decadencia" de 1933 y el "desarraigo" de 1939-1941 apuntan a la falta de "espíritu" y de "ser", o de "mundo espiritual", que han alcanzado a términos como "sociedad", "comunidad", "cultura", "pueblo", "patria", "Estado" e "Iglesia". Palabras vacías y mentirosas respecto de lo que es la grandeza del pueblo alemán. Para Heidegger, como para la ideología nazi, el Idealismo alemán habría fracasado en su intento de dirigir a la nación alemana a través de un discurso filosófico moderno que ha confundido, por el olvido del Ser, la "autonomía" con una subjetividad libre de originarios compromisos con su pueblo y raza. La Universidad alema que, suponen Heidegger y los nazis (Hitler, Rosenberg, los hermanos Jünger, entre tantos otros), debe ser el alma mater y ángel custodio de ese "patrimonio nacional". O, con palabras del propio Heidegger, custodios de la pureza de esos "dominios" que ya no son "refugios" para la existencia alemana cuya República de Weimar representa al enemigo a batir para el nuevo nacionalismo alemán. Por lo tanto, "pueblo", "patria", "sociedad", "comunidad", "Estado", "Iglesia", "cultura" aparecen como carentes de un verdadero hogar que sólo les puede dar la continuidad en el Ser (alemán). He ahí el Nihilismo como resultado del olvido del Ser. Ni la filosofía, ni la ciencia, ni el arte, ni ningún ente, tienen casa propia porque se han universalizados como parte de la "caída" del Dasein en el das Man. Estos estudios que se vienen haciendo en la Universidad alemana (Hegelianismo, Marxismo, Neokantismo, Positivismo lógico y Fenomenología, por citar varios "dominios" filosóficos en el corazón de la Universidad alemana) son investigaciones sin patria, sin el hogar (Heimat) que le brinda la "historicidad"; tal y como ha sido desarrollada en Sein und Zeit. En este sentido todos estos dominios que se enseñan en la Universidad alemana se han quedado sin fundamento, "sin suelo" (Bodenlosigkeit), tal y como aparece en el $\$ 77$ de la obra citada y que desde 2005 había señalado Emmanuel Faye, 9 años antes de la aparición de los Cuadernos negros. Así, pues, debería estar claro que la "autoafirmación" de la Universidad alemana es, al mismo tiempo, el ángel exterminador que va a llevar a cabo la purificación de esos conceptos desarraigados. ¿Se entiende?

El 18 de octubre de 1916 Heidegger le escribe a su futura esposa: "la judaización de nuestra cultura y de nuestras universidades es sin 
duda espantosa, y creo que la raza alemana debería procurarse aún otro tanto de fuerza interior para llegar a la cima. iDe lo contrario el Capital!” (En Donatella Di Césare: Heidegger y los Judíos, p. 110).

En el pasaje citado de La autoafirmación de la Universidad alemana los enemigos a destruir, en aras de la conservación o cuidado del "mundo espiritual" del pueblo alemán, no aparecen señalados por sus respectivos partidos políticos sino, y esto es esencial para calibrar el antisemitismo de Heidegger, como parte esencial de la "autoafirmación" de la universidad alemana como lucha (Kampf) contra el intelectualismo judío que, desde Werner Sombart (Los judios y la vida económica, 1911), ha sido la etiqueta definitoria de la forma de vida de los judíos. He analizado este tema de la relación entre el "pensamiento abstracto" y los judíos como "pueblo nómada", es decir, un no-pueblo para la cultura alemana en Heidegger de camino al Holocausto (2008) y Cultura y barbarie. Racismo y antisemitismo (2014). Pero ahora debo matizar. Lo más importante del discurso de Rectorado de Heidegger no es la mímesis con el nazismo: "raza" y "tierra"; sino el negativo revelador de la foto. ¿Qué no puede ser "espíritu”? ¿Qué mal espíritu obstaculiza esta autoafirmación alemana?, en fin, ¿Cuál es la vida de los judíos en la universidad alemana? O con más precisión histórica, y haciéndome eco del panfleto de Richard Wagner La judeización de la música (1860): ¿En qué consiste la judeización de la Universidad alemana de la que Heidegger hace eco desde 1916?

La sagacidad vacía y el juego del intelecto que a nada compromete porque la Universidad alemana está llena de judíos, de profesores y maestros que "desarraigan" desde dentro. A lo que hay que añadir que se trata del conflicto presente en el xix alemán con los judíos "asimilados" como, por ejemplo, el fundador de la Escuela de Marburgo y neokantiano Hermann Cohen. Ya lo afirmaba Wagner: no se trata de estar con los alemanes; sino "entre" los alemanes. Algo imposible de llevar a cabo por los judíos y razón por la que su música, Mendelshon, por ejemplo, carecía del tono vital alemán. Echando a perder, desde las sinagogas, el ser de la música originariamente alemana.

Espíritu (Geist) no es el ejercicio sin fin del análisis intelectual, tampoco una razón universal. De un plumazo quedan al descubierto los obstáculos universitarios no alemanes como el neokantismo y la fenomenología: el citado Cohen, Ernst Casirer, Edmund Husserl y demás 
judíos alemanes. También aparece como enemigo a destruir toda lógica basada en una razón universal justificada con argumentos; de manera que el positivismo lógico, el neokantismo y la fenomenología a ojos de Heidegger no son errores gnoseológicos sino una traición al espíritu alemán. Ninguna de estas escuelas vive "entre" los alemanes porque su filosofía forma parte del desarraigo y de la decadencia en tanto agentes modernos instalados como "parásitos" en el corazón de la Universidad alemana. De nada sirvió que en la I Guerra Mundial murieran, aproximadamente, 12.000 judíos en el frente; incluído uno de los hijos de Husserl.

Que el espíritu no es una superestructura cultural pone de relieve que el análisis que lleva a cabo el materialismo histórico de la dinámica de la sociedad moderna ahonda el problema del desarraigo de lo propiamente alemán-Europeo-Occidental. Este, y no otros idealismos del tipo "hermenéutica para todos los pueblos de la Tierra", como se cree en Latinoamérica, Heidegger salvador de la originalidad de cada forma de ser, es el contexto histórico, cultural y político desde el que emerge, y cobra su sentido, la filosofía de Heidegger y su pregunta por el olvido del Ser.

Tanto la filosofía como la ciencia y la política tienen que elegir entre: "universalidad" o "mundo espiritual". Disyunción exclusiva que el nazismo, cual ángel purificador de la raza pone encima de la mesa como Leyes de Núremberg en 1935. El mismo año, qué casualidad, que "el mejor pensador del siglo xx" (Jesús Adrián Escudero) se pregunta en clase "¿Por qué hay Ser y no más bien Nada?”, es decir, “¿Quiénes somos nosotros mismos?" (Introducción a la Metafísica).

Por lo tanto, de aquí se sigue, en buena lógica, la repetición de la aporía política del nazismo: nacional-socialista; de la misma forma que para salvar el "mundo espiritual" del pueblo alemán tanto la ciencia como la filosofía (la política, el derecho, la religión, el arte, la economía, la medicina y demás "Facultades") han de volver a ponerse en el comienzo "nacional". ¿Cómo combatir la judeización de la Universidad alemana?: a través de un "segundo comienzo" del origen. El ataque a Husserl por parte de Heidegger solo es, nada más y nada menos, una ejemplaficación más del ataque general que se viene llevando a cabo en Alemania desde la derrota contra la judaización de Alemania. Esta judaización sería la culpable de la derrota porque por su (ma- 
la) educación los alemanes, el pueblo alemán, no habría estado a la altura del "destino" que el Ser se jugaba en esta Primera Guerra Mundial. Heidegger señala, tanto desde su cátedra como desde sus Escritos Políticos -ninguneados en español- la profunda relación filosófica del judío con "la sagacidad vacía" que nunca podrá comprometerse con las "decisiones" que afectan a la conservación del "mundo espiritual" del Volk alemán.

En este primer párrafo del texto aparece la cuestión del ente en relación a la "decadencia" que sufren esos términos fundamentales "cultura", "patria", "pueblo", "sociedad", "comunidad", "Estado" e "Iglesia" que se han quedado al borde del abismo (Ab-grund), si es que ya están dentro del ciclón universalista del desarraigo. Algunos tardíos románticos aún podrían seguir creyendo en la atracción de la muerte como abismo del ser. Nada de esto. La radical finitud del Ser del pueblo alemán no da para lamentos, ni nostalgias, ni flirteos posmodernos con ese abismo deconstructor: dejar de ser como le ocurrirá a toda persona porque el hombre es mortal. Ese tipo de "vacío" carece de interés para Heidegger. Lo que en el Ab-grund está en juego es la judaización del Ser. Contra esta "falta de suelo" de toda la filosofía de Occidente Heidegger va a emprender la tarea inversa, contraria, a través de una analítica existencial en la que el hombre, a través de su pueblo histórico, está, o debería estar, encadenado. Dasein-Volk-BodenBlut-Schprach-Tod-Staat.

Para entender a Heidegger, y así poder renunciar a él desde su propia forma de pensar, tenemos que partir de la crítica que Herder (Otra filosofía de la historia para la educación de la humanidad) y Nietzsche (Verdad y mentira en sentido extra-moral) llevaron a cabo como parte de sus críticas respectivas a "la igualación de lo desigual" (Nietzsche). En este sentido las ideas, que tienden a la universalidad desde Platón, aparecen a los ojos de Heidegger como el vehículo científico y filosófico amén de político de la modernidad en tanto revolución contra la tradición. La visión del mundo propia de la modernidad tiene un concepto de la verdad, una teoría sobre la verdad, basada en el mundo como ente (عï̄os que también significa "imágen”). Aquel inicio (ya mal inicio para Heidegger) de la filosofía: "Nadie entre aquí sin saber matemáticas" convierte al mundo en una "idea". La geometría de Descartes, la razón universal de Spinoza, el principio de Razón suficiente de Leib- 
niz, la sociedad civil de Locke, el escepticismo ilustrado de Hume, la Dialéctica Trascendental y cosmpolita de Kant, la Dialéctica de la historia (Hegel-Marx), la genealogía de Nietzsche-Foucault que nos hace sospechar tanto del . rigençomo de la propia "historia", la libertad y el pacifismo de J. S. Mill, la intencionalidad de Husserl que es una flecha lanzada más allá de cualquier identidad nacionalista, en fin, la lista es muy larga, el existencialismo humanista (para todos) de un Sartre que nos comparte, al describirla, la náusea, señalamientos que no agotan, ni mucho menos, la riqueza plural de los modernos y en cuyo acervo nos es fundamental la historia revolucionaria de la ciencia moderna, Copérnico, Kepler y Galileo entre tantos otros como Newton... y Darwin, y Einstein. iComo para poner el destino de la Tierra y el del hombre en función del Boden como si de toda la vida hubiéramos estado ahí (Da), suelo natal, patria, comunidad, hogar; cuando sabemos que todo nacionalismo solo es un invento histórico cultural tal y como dicen Fernando Savater (El mito del origen) y Jesús Turiso (El ser genuflexo).

Pero para Heidegger -justamente - la "visión" del mundo y del hombre, un animal de ideas que siempre anda más allá de "sí mismo", se convierte en la prueba esencial para montar su historia del olvido del Ser. Toda la modernidad es la prueba de la decadencia y desarraigo de Occidente, de Europa, porque tanto la ciencia como la filosofía y la política son hijas de lo que denomina la "entificación" del Ser. A la pregunta fundamental de la metafísica, “ ¿Por qué hay ente y no más bien nada?”, punto de partida de su Introducción a la -Metafísica (1935), Heidegger no responde con otro ente u otra ïdea"( con la siempre penúltima "teoría" acerca del sentido y estructura de ese ente, ya sea económico, lógico, histórico, moral o estético. Todo esto no dejan de ser "ideas" que igualan lo desigual (animal político, animal racional, mortal y libre) y, por lo tanto, "conceptos" cuya dinámica conlleva una universalidad en donde lo originario de la existencia, la raza, el Ser, se pierde en el Nihilismo filosófico, científico, religioso y político de la Democracia.

A partir de este comentario de texto cobra sentido político, Gran Política, una hermenéutica de la facticidad histórica o historicidad del Ser. Es importante comprender el sentido y la estructura del ente a través del cual se desvela el mundo; pero la pregunta fundamental no 
gira en torno al ente, sino en torno al Ser que es su auténtico Grund o "suelo" (Boden). “¿Por qué hay Ser y no más bien Nada?” ya no espera otra teoría sino la "decisión" o "lucha" por el Ser. ¿Cuál es la batalla y el campo de batalla de esta Kampf?: o el Ser o las ideas.

Déjenme hacer un paréntesis cinematográfico. Spielberg llevó en 2012 a la pantalla el libro de Doris Kearm Good win Team of Rivals. The Political Genius of Abraham Lincoln. En esencia Lincoln de Spielberg nos hace entrar en el mundo de la deliberación con todas sus limitaciones y contingencias. Este director nos representa lo que estaba en juego en 1863, que no es sin más la Décimotercera Enmienda gracias a la que aquellos 4 millones de esclavos negros pasarían a ser libres. Esto era cierto, pero lo que estaba en juego era el fundamento racional del humanismo. No se trataba de un arrebato sentimental, sino de una deuda que este hombre, presidente de los Estados Unidos, tenía con la "razón humana". Por eso no nos debe extrañar que, en uno de los momentos álgidos de la cinta, Lincoln se base en los razonamientos de Euclides para amonestar a sus propios compañeros de gabinete que dudaban no ya de la "oportunidad" de promover esa Enmienda antes de que acabe la guerra y el mandato presidencial, sino, lo peor, que no ven con la claridad racional que la Enmienda se proponga contra viento y marea. iAcción!: "Dos cosas iguales entre sí -rumía el actor en voz alta- y esta, a su vez, igual a una tercera, son iguales entre sí". Se trata, exclama Lincoln, "de una verdad autoevidente". Desde los bancos proesclavistas se le acusa de "tirano" y de haberse convertido en "su majestad Abraham i el africano”. Para que los amables lectores de mi ensayo hagan clic con el racismo de Heidegger, les recomiendo la escena, ya casi al final de la película, en la que el representante del Sur le propone a Lincoln este intercambio: "la paz por nuestro derecho a paralizar la Enmienda”. Y Lincoln le contesta que el Sur no es una nación; sino un lugar de EEUU en donde unos rebeldes quieren enfrentarse a la Constitución. Entonces el representante, abatidamente desesperado, hace un último esfuerzo amparándose en algo así como la "historicidad" de Heidegger: "perderemos nuestra economía", "perderemos nuestras tradiciones"... y Lincoln le rebate con calma: "la esclavitud ha sido derogada". Lo que no significa otra cosa -advierte Lincoln a los de su propio partido- que la vida vuelve a abrirse desde sus propias problemáticas nuevas. Que viene al hilo de la incertidumbre y 
pesimismo que se apoderan de sus propios compañeros de gabinete: entonces, los negros también votaran. "Y, entonces, ¿qué haremos?" -le preguntan al presidente. "Entonces -contesta- habrá que avanzar a base de tener que improvisar".

¿No será el humanismo de la igualdad de todos los seres humanos una "idea" que hace del propio ser humano una perpetua Enmienda a partir de principios morales basados en la propia lógica de la razón?

El 20 de junio de 1932 -prácticamente un año antes de la toma de posesión como rector- Heidegger le dice a Elfride desde Friburgo lo siguiente: "aun cuando el esfuerzo que exigen los nazis es grande, será siempre mejor que este pernicioso envenenamiento al que hemos sido expuestos durante las décadas pasadas bajo el lema de 'cultura' y 'espiritu”' (Heidegger, G (ed.): “i!Alma mí!”. Cartas de Martin Heidegger a su mujer Elfride (1915-1970). Manantial. Buenos Aires, p. 130. Citado por Donatela Di Cesara: oc., p. 112. Las cursivas son mías).

De forma autobiográfica recuperamos el problema, la cuestión filosófica, el problema del Ser. Los siete términos del principio de este texto que, decíamos con Sein und Zeit, están en decadencia por ser expresiones vacías, carentes de "suelo" (Bodenlosigkeit): "patria", "cultura", "pueblo", "Estado", "Iglesia”, "comunidad" y "sociedad", ahora (y haciendo pie en la carta que acabamos de citar) podemos, por un lado, sintetizar lo que para Heiedegger era el tema de su tiempo: el envenenamiento que la judaización de la Kultury del Geisthan provocado en las últimas décadas. Suficiente para sostener, como vengo haciendo junto a otros investigadores, que la intencionalidad de la Obra de Heidegger no se entiende al margen de la lucha por la reconquista de una çulturaz . ${ }^{\text {es }}$ píritu. ${ }^{\mathrm{a}}$ uténticamente alemanes, europeos, occidentales. Lo que exige, filosófica y políticamente, una "vuelta. ${ }^{\mathrm{a} l}$ comienzo del Ser.

Por esta razón Heidegger se pregunta en el texto ( $2^{\circ}$ párrafo) por las condiciones que podrían "despertar" el ancestral "temor" ante la posible pérdida de "la hegemonía de lo existente", así como la conciencia histórica de esta "indigencia frente a las decisiones". El estilo heideggeriano es muy oscuro y su "jerga de la autenticidad" (Adorno) nos exige de cierta micro hermenéutica. Así, para Heidegger, esta situación histórica en la que está Alemania y el mundo aparece como un Hermes bifronte: a) testigo y testimonio no ya de la "destrucción"; sino de la "devastación" que la judaización del "espíritu" y la "cultura" han 
provocado en la vida alemana; sino que b) ese mismo "testimonio" debe transformarse en el nuevo espacio y tiempo que haga posible, desde Alemania, "las preguntas de la reflexión".

El que Heidegger aceptara el nazismo como solución de la crisis alemana de la cultura y el espíritu no significó, es cierto, una entrega a las "totalidades" del mismo porque su filosofía del Ser es radicalmente finita y excluyente: no se puede exportar. De ahí que manifieste que lo importante no es seguir la línea que marca la finalidad histórica de un Übermensch o perfección de un animal biológico. ¿Por qué? Porque la biología moderna es, fundamentalmente, un ente sin patria, sin suelo, en fin, un Bodenlosigkeit. Otro pensamiento sin suelo con el que el Das Man -del que no escapa el nazismo vulgar- aspira desde su total desconocimiento de la pregunta por el Ser a llevar a cabo una política en base a la "perfección" del animal definitivamente fijado. La biología moderna, lo supo Heidegger, va en la dirección contraria: la vida abierta a una pluralidad incalculable e incorsetable a una única y última definición. Lo que Heidegger añora, más allá del Übermensch, y de todo Über o ir más allá de sí mismo, es el hombre y el mundo que había (para la quimera del "origen") antes del desarraigo con el Ser. Dicho en otros términos: la "jerarquía" que confusamente busca el nacionalsocialismo no puede venir de más entifafción del Ser; sino de la destrucción de la época de la "imágen" del mundo gracias a lo que el "espíritu" y la "cultura" alemanas han caído en un casi total "desarraigo". El problema del Ser (y aunque la selección del hombre sea necesaria) no se ubica en ninguna ciencia moderna; sino, son palabras de Heidegger, "en el carácter metafísico del ser en su totalidad". Este "carácter metafísco" del Ser conlleva una praxis que nada, absolutamente nada, tiene que ver con la deliberación; sino con la "osadía" más fría. Tanto que hay que rechazar cualquier valoración de orden

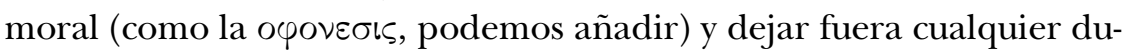
da que aparezca a través del "pesimismo", porque "la mirada filosófica tiene que tener enfrente y a su alrededor la perfección de la historia metafísica del ser" para que renazca el "aire" que posibilite poder de nuevo tomar "las decisiones iniciales" a través de las cuáles la cultura y el espíritu puedan volver a ser los guardianes que alguna vez fueron.

Y es que, para Heidegger, la devastación llevada a cabo por la raza judía de la cultura y espíritu propiamente alemanes hasta su desarrai- 
go, mundialización, cosmopolitismo, infinitud y universalidad, habría pegado más en la "educación" y "sector cultural" que en cualquier otra parte ( $3^{\circ}$ párrafo). Ahí tenemos al descubierto la intencionalidad (que nunca ocultó Heidegger) de una hermenéutica en busca del "origen" de los conceptos auténticamente griegos; tarea que comienza en los años 20 con su "estrategia de desmontaje" de las interpretaciones recibidas de los griegos como parte de una experiencia "inauténtica" de aquellos "arquetipos" de la vida. Desde 1922 Heidegger sabe cómo destruir al enemigo de la verdadera tradición espiritual alemana que son los griegos. Toda su filosofía es una reconquista de los griegos frente a las "interpretaciones heterogéneeas" que en su nombre se han dado de la "vida" y de la "sustancia". "La hermenéutica, pues, cumple su tarea sólo a través de la destrucción (Destruktion)" (M. Heidegger: Informe Natorp, p. 51. Cursivas en el original). Desde estos Cuadernos negros vemos confirmadas, por el propio Heidegger, nuestras tesis. La Obra de Heidegger no se entiende al margen de su antisemitismo. ¿De quién es Platón?; ¿de quién Aristóteles?, ¿de quién Kant y Nietzsche?; en fin, ¿de quién es Hölderlin? Frente a esas "décadas" en las que la cultura y el espíritu alemanes han ido siendo educados universitariamente en el "desarraigo", Heidegger opone esta hermenéutica de la facticidad del Ser como Dasein que hay que recuperaren toda su pureza histórica. Lo que pasa, por ejemplo, por una interpretación "fenomenológica" de Aristóteles que haga de la ovøı no una "sustancia"; sino "bienes patrimoniales" y "bienes familiares" (Informe Natorp, p. 58) con lo que, muy hábilmente, deconstruye, destruye, el alcance trascendental que tenía la "sustancia" para hacer de ella un bien nacional de la que, como veremos, la raza judía está radicalmente fuera.

Lo explica con claridad, ahora sí, al inicio del $3^{\circ}$ párrafo cuando al señalar la "devastación” de la cultura alemana - "con los inútiles guardianes de la herencia espiritual”- señala, al mismo tiempo, la escuela que ha ido dejando esta situación: "una habilidad mayor de renuncia a la reflexión esencial".

Tengo aquí que llamar la atención sobre el término "habilidad" como una de las etiquetas emblemáticas acuñada por Sombarten 1911, Los Judíos y la vida económica, para distinguir la forma de pensamiento que se da entre los pueblos alemanes y los pueblos semitas. Siguiendo a Sombart podemos hacer esta división. Alemanes: Producción- 
Pensar-Comunidad (orgánico-viviente). Judíos: Circulación-CalcularSociedad (contractual sin alma). Y dos paisajes que se contraponen como el "bosque" (alemán) y el "desierto" (judío). El hecho que todo se vuelva "cantidad" y "cuantificación”, afirmó Sombart, se debe a que en la "base" del judío se produce una perversión fundamental: la "negociación" disuelve la "actuación" de una economía personal, es decir, propiamente nacional. Por lo que, y en general, toda la actividad económica mundial, gracias al capitalismo, se ha transformado en "un asunto puramente intelectual". ${ }^{1}$ La fuente de Heidegger, aunque no lo cite, es Sombart. "Heidegger retoma todos estos motivos", afirma Di Cesare, aunque en el paisaje ha habido un importante cambio. Ahora "el vínculo con su madre 'suaba' confluye en el lenguaje de su pensamiento, que sigue la senda abierta por Hölderlin” (oc., p. 131).

La “devastación” de la cultura alemana y la "habilidad" para el cálculo como forma de no pensar en lo esencial formar un binomio en el que al mismo tiempo se da esta situación: a) la eliminación de todos los "dominios" de arraigo (patria, cultura, espíritu, sociedad, comunidad, Estado, Iglesia... y lengua) se desvanecen engullidos por ese "empoderamientode acciones universales", y b) la renuncia del "hombre masa" a la pregunta por el Ser, esto es, "a la pretensión de decisiones y normas". Ahí, dice Heidegger, surge "un vacío invisible". ¿Por qué el Nihilismo es "invisible"? Porque hasta Heidegger no ha sido pensado a través de la historia del olvido del Ser. Este "vacío" es "invisible" porque desde determinada percepción del mundo y del hombre es imposible verlo, sentirlo. Esta invisibilidad respecto del vacío (de Ser) no puede aparecer en la época de la imagen del mundo porque, precisamente, es esta "metafísica" la que aún sigue rigiendo y que se encarga de ocultar habilidosamente a través de una pseudo acción del pseudo pensamiento racional-calculador cuya intencionalidad sobrepasa, va más allá de la facticidad del Dasein-Volk-Boden-Blut-SchprachStaat. El Ser, entonces, se ha perdido por la metafísica; una mala, perversa, metafísica que directamente ayuda al mantenimiento del olvido del Ser como parte de una "maquinación" mundial. Todo lo que conlleva un ejercicio de totalidades y universalismo, esencia de la me-

${ }^{1}$ Cf. Herf, J., El modernismo reaccionario. Tecnología, cultura y política en Weimar y el Tercer Reich, p. 289; Quesada, J., Heidegger de camino al Holocausto, p. 34 y 31. 
tafísica, es, precisamente, la causa de que aquél vacío se haya hecho invisible.

Encuentro pasajes difíciles por todo lo que Heidegger dice y no dice. Al fin y al cabo son fragmentos de pensamiento nada lineales, apuntes autobiográficos en donde Heidegger se explica (a sí mismo). Por lo tanto, da muchas cosas por obvias para un lector inmerso en la situación cultural y espiritual de Alemania. Por ejemplo, la diferencia y crítica que establece entre la "soldadesca" actual y el "guerrero" de los últimos años de la anterior guerra mundial. Hay un aire jüngeriano en esta apología del "Prusianismo" del que, como parte del desarraigo del Ser, cree, equivocadamente, la "soldadesca" venir de ese espíritu guerrero. Pero, ¿qué puede tener esto que ver con la crítica heideggeriana a la metafísica? "Veo muchos soldados: imuchos guerreros es lo que yo quisiera ver! 'Uni-forme' se llama lo que llevan puesto: iojalá no sea uni-formidad lo que con ello encubres". Se trata de Nietzsche a finales del xix en De la guerra y el pueblo guerrero perteneciente a la Primera Parte de Asi habló Zaratustra (p. 79). ¿Quién es un guerrero? "La guerra y el valor han hecho más cosas grandes que el amor al prójimo. No vuestra compasión, sino vuestra valentía es la que ha salvado hasta ahora a quienes se hallaban en peligro" (p. 80. Cursivas nuestras).Para Heidegger lo que queda claro es que de esta "soldadesca", y a pesar de que se anteponga la "muerte" a la "penuria" de una vida, no obstante, de esa acción "no podrán surgir decisiones históricas creativas" porque estarían basadas en "la ignorancia burda de la esencia del ser", es decir, en ese aire de totalidades que ignora la verdad del Ser. ¿Podríamos establecer una analogía entre: a) la crítica de la metafísica como "totalidad" y b) la diferencia entre "soldado" y "guerrero"? ¿La crítica a la metafísica no requiere "soldados" sino "guerreros"? Entonces, la crítica a la metafísica es como la crítica al amor al prójimo?

Esta autocrítica no significaba, ni mucho menos, un aval para el "pacifismo" y el "liberalismo" porque se tratan, ya lo podemos decir, de la misma "maquinación" que ha llevado a cabo la uni-formidad del Ser. Lo que implica necesariamente una imposibilidad radical a la hora de avanzar, escribe Heidegger, "hacia el dominio de las decisiones esenciales".

A partir de aquí (estamos ya en el $4^{\circ}$ parágrafo del texto) Heidegger reivindica un antisemitismo nada vulgar para implicar, de su pluma y 
letra, el antisemitismo como expresión alemana de la crítica a la metafísica de Occidente. Y lo hace resaltando, precisamente, el papel del judaísmo en la historia del olvido del Ser. Que Heidegger estaba convencido entre 1939 y 1941 de que el poderío de la maquinación judía contra el Ser había llegado a su fin, lo demuestran los tiempos empleados en la descripción de la situación: "el temporal aumento en el poderío de los judíos". Obvio, el final de la filosofía se correlaciona con el final de este poder. Siendo la propia "modernidad" la que le da asilo espiritual al parásito judío que se ha instalado, a través de su "habilidad" aritmética (o "abstracta” como afirmó Sombart), en el corazón de centro Europa. ¿Cómo pudo un pueblo nómada hacerse cargo del "espíritu" y de la "cultura"? Por el punto de apoyo que le daba la subjetividad moderna capaz - por la verdad del ente (ciencias) - de dejar atrás, superar, la patria, el suelo, la sangre, la comunidad, la lengua, la Iglesia y hasta el Estado. Vuelve a repetir Heidegger lo del "vacío" que ahora se nos hace visible: los judíos se han podido instalar durante décadas en la Universidad alemana porque anteponen la verdad a la patria y la filosofía al Estado. De tal forma que, en medio de la revolución nazi que se lleva a cabo en Alemania, Heidegger reflexiona sobre el porvenir de la metafísica afirmando (desde una inequívoca victoria de Alemania) que en la medida en que se avance hacia las preguntas y decisiones fundamentales, resulta obvio que a la raza (Rasse) judía le serán completamente inaccesibles los dominios existenciales recuperados para lo auténticamente aleman, como la patria, la cultura, el pueblo, el Estado, la Iglesia, la sociedad, la comunidad, en fin, el espíritu.

El paréntesis que a continuación montó Heidegger es un corolario de su tesis en la que explica su "ataque" a Husserl. No cabe duda, aseguró el alumno, que el maestro de la fenomenología tenía razón en la crítica del psicologismo. Pero la fenomenología de Husserl "no llega para nada a los dominios de las decisiones esenciales" porque, de raíz racial, está imposibilitado para ello. Una muestra de ello sería su acercamiento a la filosofía trascendental neokantiana. Ahora lo importante no es entrar en el detalle de la crítica de Husserl al neokantismo porque lo que une, por encima del nazismo, a Hermann Cohen con Edmund Husserl es la continuidad filosófica del sujeto trascendental, de un sujeto que va más allá de sí mismo. 
Por eso Heidegger es consciente de que su ataque a Husserl va más allá de una diferencia entre alumno y maestro. Jamás la fenomenología los había unido, como creyó Husserl; sino que había una diferencia ontológica o metafísica insalvable desde el principio. Husserl aparece en este fragmento como parte esencial de la crítica a un pensamiento abstracto, indiferente, hacia el Estado y la patria. No ve a Husserl como un alemán más; sino como una existencia andante del olvido del Ser que, durante décadas, se había "alojado" en la cultura y espíritu de Alemania. La crítica a todo lo que representaba Husserl se ubicó "un momento histórico de la más elevada decisión respecto de la prioridad del ser y el establecimiento de la verdad del ser".

Por lo que este guerrero del saber histórico careció de la menor compasión hacia su maestro, mentor y amigo. $\mathrm{Y}$ al matar al padre llegó tanto el final de la filosofía como el nazismo en tanto acontecimiento (Ereignis). ¿Cuál tenía que ser la reflexión esencial?: “¿Por qué hay Ser y no más bien Nada?”. ¿Cuál la decisión esencial a la que no pueden acceder los judíos?: “¿Quiénes somos nosotros mismos?”

\section{Políticas de la "epoché"}

Por lo tanto, en la epoché nos encontramos con una política del Ser diametralmente opuesta a la que se despliega como facticidad histórica del "ser-Ahí" en su alumno Heidegger. Si el maestro enseña en la Universidad a poner entre paréntesis el $D a$ para reactivar la trascendentalidad que los une a pesar de sus diferencias de "origen"; el alumno, inscrito en el "contra movimiento", anhela la pureza de lo finito, limitida y excluyente que "es" el espíritu y la cultura de Alemania.

El "Amarás a tu prójimo como a ti mismo", ¿̇no implica hacer epoché del sí mismo para encontrarse con el Otro? ¿No es la propia acción fenomenológica del poner al mundo entre paréntesis una radical crítica contra el nacionalismo? La utopía fenomenológica que late en el proyecto husserliano de "mundo", la recuperación del "mundo de la vida cotidiana" (Lebenswelt) en la clave de su "pluralidad" e "infinitud", lo que no se puede rescatar y sostener frente a la "destrucción" (Destruktion) del mundo si no es a través de una filosofía de la intersubjetividad que al "pensar" sabe que ya está fuera de "sí mismo", esta actitud filosófica, ¿no es la clave para entender la diferencia ontológica y política entre las "interpretaciones fenomenológicas" que Heidegger 
hace del mundo y de la historia de la filosofía occidental, y la "fenomenología" de Husserl? Y esta nueva actitud filosófica ante el mundo, ¿no es el motor que provoca la "autoafirmación" de la Universidad alemana contra los intelectuales judíos que siempre serán considerados, precisamente, como malos guardianes de la cultura, críticos indiferentes respecto de las reflexiones y decisiones "esenciales" respecto de la patria, el pueblo, el estado, la cultura, el espíritu?

La política husserliana fundamentada en la necesidad de la epojé intenta, como tarea para un eterno "principiante" de la filosofía fenomenológica, reactivar la pluralidad infinita de la vida humana (abierta a todo ser viviente, como explica Julia Valentina Iribarne en "La antigua y difícil propuesta del amor", en La fenomenología como monadología; y lamento no poder dar el nombre de la autora o autor de la referencia a la fenomenóloga argentina porque se trata de un artículo, "Fenomenología del amor", al que he tenido acceso gracias a una evaluación) contra el ordenamiento finito, limitado y excluyente de unos pueblos contra otros. Heidegger sabía, pues, que su ataque "contra" (gegen) Husserl había que inscribirlo, al menos según él, en la lucha por el Ser (Seyn); de forma que la "autoafirmación" del espíritu alemán era parte esencial del contra movimiento filosófico existencial (Dasein-BodenSchprach-Blut-Volk-Staat). Siendo el antisemitismo, su antisemitismo ontológico, lo que le va a separar radicalmente tanto de Husserl como del existencialismo humanista de Sartre. "Historicidad" y "antisemitismo" son las dos caras de la misma moneda. El ataque contra su maestro y mentor es, al mismo tiempo, el ataque a un "inútil" guardián de la cultura alemana. Inutilidad que percibe, a la luz de "su" historia de la filosofía, como parte de una "maquinación" de orden mundial contra el Seyn.

Para Heidegger, Husserl era, a pesar de su acertada crítica al psicologismo, un fenomenólogo: alguien capaz de poner entre paréntesis nuestras diferencias para ir a lo esencial: "Espíritu común" (Gemeingeist) - tal y como lo ha estudiado Julia Valentina Iribarne. Si este espíritu común (de una rica plasticidad que invita, precisamente, a no destruir al Otro conmigo) hubiera entrado en contacto con Heidegger, difícilmente se habría afiliado al nacionalsocialismo y difícilmente habría dejado a su maestro y amigo solo ante el peligro. Pero, ay, la intersubjetividad husserliana era un obstáculo (y parte de la maquina- 
ción del Judío) para la "autoafirmación”. Había que decapitar al padre por doble motivo: era "judío” y "fenomenólogo".

Así, pues, estamos ante dos políticas de la epoché bien diferentes tanto a nivel filosófico como político. Y esto no es un tema baladí o meramente académico; sino que, en mi opinión, forma una de las clave para comprender el tema de nuestro tiempo. Aquella Krisis aparece en el siglo xxi tal y como Heidegger lo dejó expuesto al final del texto que estamos comentando. Su ataque contra Husserl solo es la punta del iceberg de su ataque a la esencia de la metafísica que tendería a desarraigar a todas las patrias y razas del mundo. Aquel ataque como "momento histórico" entrañaba una decisión por lo esencial: o el ser o el Seyn. También: o la prioridad del ser como universal o la implantación de la verdad del Dasein-Volk-Staat. O epoché o nacionalismo. En fin: o Espíritu común o Destruktion. Y es que, estarán de acuerdo conmigo, el mundo se balcaniza cada vez más. Todos quieren ser desiguales y con base en la "diferencia ontológica" que hace furor entre los que quieren seguir en el "bucle melancólico" en el que se les educa como identidad olvidada en cada "laberinto de la soledad", el mundo parece gravitar, anti-fenomenológicamente, en razón de la diferencia insalvable. No una gratísima diferencia desde la que nos atrae el Otro; sino una diferencia metafísica, ontológica, que no se puede poner entre paréntesis para percibir lo que, a pesar de todo, nos parecemos. El siglo xxi tiene que ser, por supervivencia, un siglo fenomenológico.

\section{Referencias}

Anónimo, 2018, “Fenomenología del amor”, en prensa.

Cohen, H., 2004, El Prójimo, Anthropos, Barcelona.

Di Cesare, D., 2017, Heidegger y los judios. Los Cuadernos negros, Gedisa, Barcelona.

Faye, E., 2009, Heidegger, la introducción del nazismo en la filosofía. En torno a los seminarios inéditos de 1933-1935, Ediciones Akal, Madrid.

Heidegger, M., 2015, Cuadernos Negros 1931-1936, trad. Alberto Cirlo, Editorial Trotta, Madrid.

—, 2014, Gesemtausgabe GA 96, ed. Vittorio Klostermann, Verlag Klostermann, Fráncfort del Meno.

—, 2012, Ser y Tiempo, trad. Jorge Eduardo Rivera, Editorial Trotta, Madrid.

—, 2002, Interpretaciones fenomenológicas sobre Aristóteles. Indicación de la situación hermenéutica (Informe Natorp), trad. Jesús Adrián Escudero, Editorial Trotta, Madrid. 
—, 1996, Discurso del rectorado. La autoafirmación de la Universidad alemana, trad. prólogo y notas Ramón Rodríguez, Editorial Técnos, Madrid.

—, 1955, Introducción a la metafísica, trad. Emilio Estiú, Editorial Nova, Buenos Aires.

Herder, J. G., 2007, Otra filosofía de la historia para la educación de la humanidad, Editorial Nova, Buenos Aires.

Herf, J., 1990, El modernismo reaccionario.Tecnología, cultura y política en Weimar y el Tercer Reich, Fondo de Cultura Económica, México.

Inverso, H. G., 2014, El mundo entre paréntesis. Una arqueología de las nociones de reducción y corporalidad, Prometeo, Buenos Aires.

Iribarne, J. V., 2002, La fenomenología como monadología, Academia Nacional de Ciencias de Argentina, Buenos Aires.

Nietzsche, F., 2003, Asi habló Zaratustra, trad. introducción y notas Andrés Sánchez Pascual, Alianza Editorial, Madrid.

- 2017, Sobre verdad y mentira en sentido extramoral y otros fragmentos de filosofía del conocimiento, Editorial Técnos, Madrid.

Quesada, J., 2008, Heidegger de camino al Holocausto, Biblioteca Nueva, Madrid.

—, 2015, Cultura y barbarie. Racismo y antisemitismo en Martin Heidegger, Biblioteca Nueva, Madrid.

Platón, 1998, Diálogos: República, vol. Iv, trad. Conrado Eggers Lan, Gredos, Madrid.

Savater, F., 1996, El mito nacionalista, Alianza Editorial, Madrid.

Schuhmann, K., 2009, Husserl y lo político. La filosofía husserliana del Estado, trad. Julia Valentina Iribarne, Prometeo, Buenos Aires.

Sombart, W., 1981, Los judios y la vida económica. La correlación del capitalismo con el judaísmo, Ediciones Cuatro Espadas, Argentina.

Rockmore, T., 1997, On Heidegger's Nazism and Philosophy, University of California Press, California.

Turiso, J., 2018, El ser genuflexo como condición posmoderna. Cultura, identidad y mentalidades, Universidad Veracruzana, Veracruz.

Wagner, R., 2013, El judaísmo en la música, trad. Rosa Sala Rose, Hermida Editores, Madrid. 